\title{
Prevalence and associated factors of ischemic heart disease (IHD) among patients with diabetes mellitus: a nation- wide, cross-sectional survey
}

\author{
Boonsub Sakboonyarat ${ }^{*}$ (D) and Ram Rangsin
}

\begin{abstract}
Background: Ischemic Heart Disease (IHD) is the first ranked among most common causes of death involving cardiovascular and other diseases. The information on the prevalence of IHD in Thailand is lacking especially among patients with diabetes mellitus. The objectives of this study were to determine the prevalence of IHD among patients with diabetes mellitus and to determine factors associated with IHD in a nation-wide survey.

Methods: A cross-sectional study to assess national outcomes among patients with diabetes who visited 831 public hospitals in Thailand was conducted in 2013 to evaluate status of care among patients with diabetes aged at least 18 years who received medical treatment in the target hospital for the last 12 months.

Results: A total of 25,902 patients with diabetes were included in this study. IHD was detected among 918 patients (3.54\%; 95\% Cl 3.32-3.77). Multivariate analysis was conducted to determine which factors were most associated with IHD, and the results showed age (AORs 1.05; 95\%Cl 1.04-1.05), being male (AORs 1.78; 95\%Cl 1.53-2.07), hypertensive comorbidity (AORs 2.10; 95\%Cl 1.68-2.62), being in Health Region 4 (AORs 1.93; 95\%Cl 1.54-2.35), presenting hyperglycemic crisis (AORs 1.53; 95\%Cl 1.14-2.06) and insulin therapy (AORs 1.40; 95\%Cl 1.17-1.66) were the highest associated factors for IHD in this population.

Conclusion: Our data emphasized that IHD was a problem among patients with diabetes. Diabetic patients should be regularly assessed for IHD and their risk factors should be better controlled. Moreover, the Ministry of Public Health managers and clinicians should provide further preventative strategies to attenuate cardiovascular disease.
\end{abstract}

Keywords: Ischemic heart disease, Diabetes mellitus, Nation-wide survey, Prevalence, Associated factors

\section{Background}

Ischemic Heart Disease (IHD) is the first ranked and most common cause of death in cardiovascular and overall diseases [1]. The estimated prevalence of IHD among people aged $\geq 18$ years in 2013 was 6.1, 6.4, 5.3 and $3.7 \%$ in Caucasian, African, Latino and Asian populations, respectively [1]. The prevalence increased with age and more prevalence was noted among males [2]. One recent study showed that the number of estimated deaths caused by IHD in Southeast Asia increased from 5.73 to 8.14 million from 1990 to 2013 [3]. Prevalence of

\footnotetext{
* Correspondence: Boonsub1991@pcm.ac.th

Department of Military and Community Medicine, Phramongkutklao College

of Medicine, Bangkok 10400, Thailand
}

IHD increased in patients with potential risk factors such as diabetes mellitus [4,5]. Globally, adults with diabetes total 381 million. The estimated global prevalence of diabetes mellitus among adult populations was 8.3, 9.6, 5.7, 6.8, 8.6 and 6.4\% in North American and Caribbean (NAC), African, European, Western Pacific and Thai populations [6]. Diabetes mellitus increases independent risk of IHD approximately 1.5 and 1.7 fold among males and females, respectively [7]. In 2007, a related study conducted among patients with diabetes reported that the age-standardized incidence rate (per 1000 person-years) of first coronary heart disease (CHD) events was 28.8 among males and 23.3 among females [8].

(c) The Author(s). 2018 Open Access This article is distributed under the terms of the Creative Commons Attribution 4.0 International License (http://creativecommons.org/licenses/by/4.0/), which permits unrestricted use, distribution, and 
Epidemiological data of IHD in Asian populations has been studied in many countries. From 2007 to 2008, the prevalence of CHD in China was $0.63 \%$ [9]. In 2002, the overall prevalence of $\mathrm{CHD}$ in India was $8.2 \%$ [10]. However, limited information is available regarding the prevalence of IHD in the Thai general population in 1991 was $0.99 \%$ [11], especially among patients with major risk factors such as diabetes mellitus. We determined the prevalence of IHD among patients with diabetes mellitus using a nation-wide, cross-sectional survey among patients with diabetes mellitus. The secondary objective of this study was to determine factors associated with IHD.

\section{Methods}

\section{Study designs}

The data of this study were retrieved from database: An assessment in Quality of Care among Patients Diagnosed with Type2 Diabetes and Hypertension Visiting Ministry of Public Health and Bangkok Metropolitan Administration Hospital in Thailand (Thailand DM/HT) after the permission of the Medical Research Network of the Consortium of Thai Medical Schools (MedResNet).

The Thailand DM/HT evaluation survey was a nation-wide, cross-sectional study aiming to assess outcomes among patients with diabetes visiting public hospitals of the Ministry of Public Health (MoPH), Thailand and private hospitals and clinics in Bangkok was conducted from 2012 to 2013. The main objective of the Thailand DM/HT evaluation survey was to evaluate the status of care and was supported by the Thai National Health Security Office (NHSO).

\section{Subjects}

The healthcare system in Thailand can be categorized in two types comprising (1) healthcare under the MoPH and (2) private healthcare such as private clinics and hospitals. All Thais have healthcare coverage schemes such as the universal coverage scheme, social insurance scheme and government officer scheme. These healthcare schemes are supported by the NHSO. All of the hospitals under the $\mathrm{MoPH}$ at all levels, i.e., community (district), general (provincial) and regional nationwide and some private clinics in Bangkok were invited to participate in the study.

A stratified two-stage cluster sampling method proportional to the size was used to select national and provincial representative samples of patients with diabetes in Thailand. The stratified sample was drawn from a subset of all MoPH hospitals in Thailand. For Bangkok, the targeted institutes included all hospitals and clinics under the NHSO. The first level (province) comprised 77 strata while the second level constituted hospitals within each province. The second level was categorized in 5 strata by size, i.e., regional center hospital (> 500 beds), provincial general (middle) hospital (200-500 beds), first level one (F1) (90-120 beds), first level two (F2) hospital (60 beds) and first level three (F3) hospital (10-30 beds). All university medical centers were excluded from this study.

Inclusion criteria for this study comprised patients with diabetes aged at least 18 years receiving hospital medical treatment in hospital, drawn using the specified sampling method, during the previous 12 months. Any patient who had participated in a clinical trial was excluded. Those patients may have received trial medication or placebo, influencing the outcome of the study.

\section{Data collection}

A total of 833 hospitals under the MoPH were categorized as 33 regional hospitals, 83 general hospitals and 717 first level or community hospitals including the first level one (F1) 73 hospitals, the first level two (F2) 126 hospitals and the first level three (F3) 518 hospitals. All regional and general hospitals were selected, as well as $10 \%$ of F1 hospitals, $20 \%$ of F3 hospitals and $70 \%$ of F3 hospitals. This faction was based on the proportion of patient care provided at the various levels of hospitals. Patients with a diagnosis of diabetes mellitus were randomized and registered at each hospital. A standardized case report form was used to obtain the required information from medical records and was sent to the Thailand DM/HT study of the Medical Research Network of the Consortium of Thai Medical Schools (MedResNet) central data management unit in Nonthaburi. Data were retrieved from patient's medical records, status of diabetes complications and results of laboratory tests.

\section{Measurements}

Data collected included demographics, weight, height, body mass index (BMI), waist circumference, smoking behavior, systolic blood pressure (SBP), diastolic blood pressure (DBP), cardiovascular complications such as left ventricular hypertrophy (LVH), diabetic complications such as diabetic retinopathy (DR) and diabetic nephropathy (DN), blood chemistry data including fasting plasma glucose (FPG), hemoglobin A1c (HbA1c), hematocrit (Hct), hemoglobin $(\mathrm{Hb})$, serum creatinine $(\mathrm{Cr})$, uric acid, lipid profile including total cholesterol (TC), triglyceride (TG), high density lipoprotein cholesterol (HDL) and low density lipoprotein cholesterol (LDL), available electrocardiogram (ECG) data and results, history of anti-hyperglycemic and antiplatelet drug use and glomerular filtration rate (GFR) calculated using the epidemiology collaboration formula (EPI). Our study enrolled those patients with diabetes who were diagnosed and received ongoing medical care in a hospital. Hospitals in Thailand normally use the standard diagnosis and treatment following Thai 
clinical practice guidelines for diabetes and diagnosis and classification of diabetes mellitus using Diabetes Care, 2010. Diabetes mellitus was defined as FPG $\geq 126 \mathrm{mg} / \mathrm{dl}$ and confirmed by repeat testing at a second visit. Fasting is defined as no caloric intake for at least $8 \mathrm{~h}$ [12]. IHD was defined as myocardial infraction or history of coronary revascularization. Diagnosis of myocardial infraction was performed using standard criteria including stable angina and acute coronary syndrome, categorized as ST-T segment elevation myocardial infraction, nonST-T segment elevation myocardial infraction and unstable angina.

\section{Statistical analysis}

Data were coded and entered in the STATA/MP for Windows, Version 12 (Stata Corp LP, TX). Categorical data were presented as number and percentage. Continuous data were presented as mean and standard deviation (SD). Prevalence was analyzed using descriptive statistics and reported as percentage and 95\% confident interval. The chi-square test was used to compare categorical data. Continuous data was compared using the $t$-test. Continuous data were grouped to analyze associated factor using odds ratio (OR). The magnitude of associations was presented as crude ORs with 95\% confidence interval. The multivariate analysis was performed using logistic regression analysis and Forward Stepwise (LR) to adjust confounders. Stepwise $p$-value for entry was 0.05 , and $p$-value for removal was set at 0.10. The Hosmer-Lemeshow goodness-of-fit of the logistic regression models was performed with $p$-value $=0.494$. The complete case analysis and imputation method were used for any missing data. Missing values were imputed based on the means of the complete case. A $p$-value less than 0.05 was considered statistically significant.

\section{Results}

\section{Demographic data}

A total of 25,902 patients with diabetes mellitus were enrolled in this study from 2012 to 2013. Average age was $60.6 \pm 10.5$ years, $8076(32.2 \%)$ were male and 17,836 (68.8\%) were female. The average diabetes duration of patients was $7.1 \pm 4.7$ years while the average HbA1c level was $8.0 \pm 2.2 \%$. Baseline characteristics of this study are shown in Table 1 . One third of participants lived in northeastern Thailand. In all, 62.5\% subjects visited community or first level (F1, F2 and F3) hospitals. In this study, patients with hypertension totaled $29.1 \%$. Prevalence of IHD among patients with diabetes was $3.54 \%$ (95\%CI 3.32-3.77), increased with older age and was more common among males. Fig. 1 shows a bar graph representing IHD prevalence for every 10 years of age separated in male, female and overall.
Associated factors of IHD among patients with diabetes Additional file 1 shows univariate analysis results regarding factors associated with IHD. Significant associated factors included older age, being male, health region, hospital level, insurance scheme, religion, occupation, GFR, HT comorbidity, HT duration, LVH, LAE, AF, DM duration, DN, DR and insulin, sulfonylurea, thiazolidinedione and aspirin therapy. Because a number of patients had missing values for $\mathrm{HbA1c}$, this may have decreased the statistical power of the complete cases analysis. As a result, we applied imputation to handle the missing value and the results of multivariate analysis after imputation showed similarity to the original independent associations with IHD. Multivariate analysis showed the risk factors of IHD included age, being male, being in Health Region 4, hypertensive comorbidity and insulin therapy (Table 2 ).

\section{Discussion}

Our present nation-wide survey showed the prevalence of IHD among Thai patients with diabetes mellitus was $3.54 \%$. IHD was significantly associated with being male, age, being in Health Region 4, hypertensive comorbidity, presenting hyperglycemic crisis and insulin therapy. To our knowledge, this is the first report on the prevalence and risk factors of IHD among Thai patients with diabetes. The prevalence of IHD was $0.99 \%$ among the general population in Thailand reported in 1991 [11]. A related study in Sweden found a much higher prevalence of IHD (21.97\%) among patients with diabetes including those aged from 45 to 74 years [13]. In contrast, our study enrolled all patients with diabetes aged from 35 to 97 years. However, when the same age groups as the Swedish study were analyzed, the prevalence of IHD was $2.75 \%$. In the general population, the prevalence of IHD in Caucasian populations is normally higher than that among Asians [1,7] and diabetes amplifies this morbidity. The present study enrolled patients with diabetes who received medical treatment in $\mathrm{MoPH}$ hospitals all over Thailand and public and private clinics in Bangkok under the NHSO. However, these populations did not include patients with diabetes who received medical treatment in health promoting hospitals (HPHs). These HPHs, primary care units of a community hospital, usually provide health care and medication for uncomplicated diabetes cases. The prevalence of IHD in this study may have been overestimated because the diabetic cases in HPHs were not included.

After adjusting for confounding factors by multivariate analysis, only older age, being male, being in Health Region 4, hypertensive comorbidity, presenting hyperglycemic crisis and insulin therapy remained significantly associated with IHD among patients with diabetes. Prevalence of IHD tended to be higher with older age similar to related studies in Sweden [13] and Finland 
Table 1 Baseline characteristics of patients (total number of subjects $=25,902$ )

\begin{tabular}{|c|c|c|}
\hline Baseline Variables & $n$ & Mean \pm SD or number (\%) \\
\hline Gender & 25,902 & \\
\hline Female & & $17,836(68.8)$ \\
\hline Male & & $8076(32.2)$ \\
\hline Age & 25,902 & $60.6 \pm 10.5$ \\
\hline Hospital level & 25,902 & \\
\hline Regional center & & $3096(12)$ \\
\hline General provincial & & $4911(19)$ \\
\hline Community & & $16,187(62.5)$ \\
\hline Bangkok metropolitan administration & & $1708(6.5)$ \\
\hline Diabetic duration & 25,902 & $7.1 \pm 4.7$ \\
\hline Waist circumference & 17,488 & $88.5 \pm 10.4$ \\
\hline Body mass index $\left(\mathrm{kg} / \mathrm{m}^{2}\right)$ & 24,643 & $25.5 \pm 4.4$ \\
\hline Fasting plasma glucose & 23,048 & $154.7 \pm 58.4$ \\
\hline $\mathrm{HbA} 1 \mathrm{c}$ level & 20,481 & $8 \pm 2.2$ \\
\hline GFR_EPI & 15,986 & $67.2 \pm 31$ \\
\hline LDL & 15,544 & $108.6 \pm 36.8$ \\
\hline $\mathrm{HDL}$ & 14,126 & $46.9 \pm 13.8$ \\
\hline Triglyceride & 15,548 & $175.4 \pm 110.9$ \\
\hline Total cholesterol & 14,775 & $187.7 \pm 44.5$ \\
\hline Uric acid & 4553 & $6.1 \pm 1.8$ \\
\hline Smoking & 23,806 & \\
\hline Never & & $21,249(89.2)$ \\
\hline Current Smoker & & $1036(4.4)$ \\
\hline Ex-smoker & & $1521(6.4)$ \\
\hline Hypertensive comorbidity & 25,902 & \\
\hline No & & $7527(29.1)$ \\
\hline Yes & & $18,375(70.9)$ \\
\hline
\end{tabular}

SD standard deviation, HbA1c hemoglobinA1c, GFR_EPI glomerular infiltration rate calculated by epidemiology collaboration formula, $L D L$ low density lipoprotein cholesterol, $H D L$ high density lipoprotein cholesterol

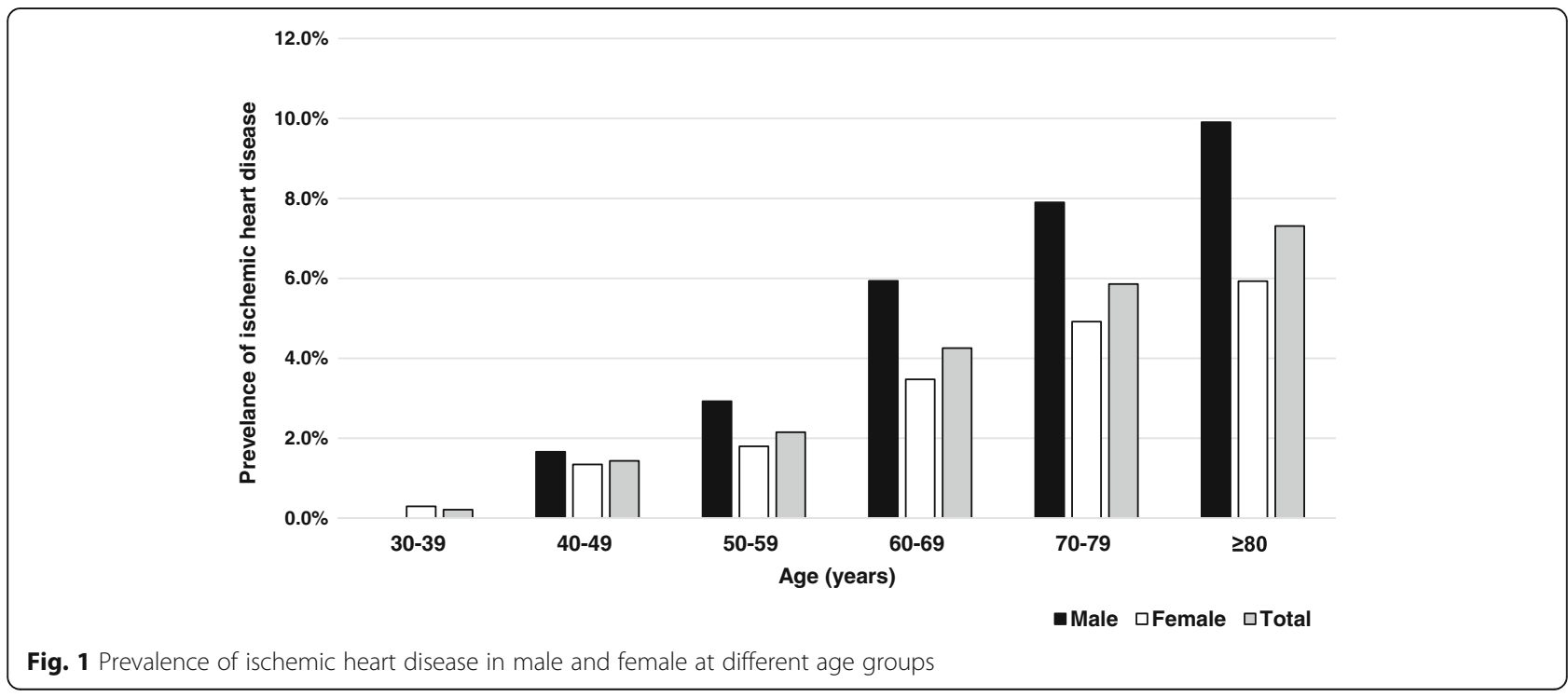


Table 2 Multivariate logistic regression for factors associated with ischemic heart disease in diabetic patients. $(N=25,902)$

\begin{tabular}{|c|c|c|c|c|}
\hline \multirow[t]{2}{*}{ Factors } & \multirow{2}{*}{$\begin{array}{l}\text { IHD } \\
n(\%)\end{array}$} & No-IHD & \multirow[t]{2}{*}{ AORs } & \multirow[t]{2}{*}{$95 \% \mathrm{Cl}$} \\
\hline & & $n(\%)$ & & \\
\hline Age (years) & $65.9 \pm 9.5$ & $60.4 \pm 10.5$ & $1.05^{\mathrm{b}}$ & $(1.04-1.05)$ \\
\hline \multicolumn{5}{|l|}{ Gender } \\
\hline Female & $523(3)$ & $17,303(97)$ & 1 & \\
\hline Male & $395(4.9)$ & $7681(95.1)$ & $1.78^{\mathrm{b}}$ & $(1.53-2.07)$ \\
\hline \multicolumn{5}{|l|}{ Health regions } \\
\hline Other health regions & $774(3.3)$ & $22,877(96.7)$ & 1 & \\
\hline The 4th health region & $144(6.4)$ & 2107 (93.6) & $1.93^{\mathrm{b}}$ & $(1.54-2.35)$ \\
\hline \multicolumn{5}{|l|}{ Hypertensive Comorbidity } \\
\hline No & $129(1.8)$ & 7398 (98.2) & 1 & \\
\hline Yes & $789(4.3)$ & $17,586(95.7)$ & $2.10^{\mathrm{b}}$ & $(1.68-2.62)$ \\
\hline \multicolumn{5}{|l|}{ Hyperglycemic crisis } \\
\hline No & $846(3.4)$ & $23,680(96.6)$ & 1 & \\
\hline Yes & $72(5.2)$ & $1304(94.8)$ & $1.53^{\mathrm{a}}$ & $(1.14-2.06)$ \\
\hline \multicolumn{5}{|l|}{ Insulin therapy } \\
\hline No & $659(3.3)$ & $19,685(96.7)$ & 1 & \\
\hline Yes & $259(4.7)$ & $5299(95.3)$ & $1.40^{\mathrm{b}}$ & $(1.17-1.66)$ \\
\hline
\end{tabular}

${ }^{a} p<0.01,{ }^{b} p<0.001$

AORs Adjusted odds ratio for age, gender, health regions, hypertensive comorbidity, duration of diabetes mellitus, hyperglycemic crisis, insulin therapy and HbA1c level, IHD Ischemic heart disease, $\mathrm{Cl}$ confidence interval

[14]. Among the elderly, changes occurring in endothelial function include loss of arterial elasticity and reduced arterial compliance, so more vascular aging and degenerative processes lead to atherosclerosis disease [15]. In addition, the endothelium experiences changed arterial function by decreased nitric oxide and increased endothelin causing a pro-coagulant state and promoting vascular smooth muscle growth and exaggerated increased risk of cardiovascular events [16]. Another reason is the elderly often have a low frequency of physical activity. A recent study showed that adults, who were physically active at least twice weekly, had decreased risk of CHD $[17,18]$.

The result of our study was similar to studies in the US and in western and Asian populations [2, 9, 19-21]. Most studies have found that IHD was more common among males than females [9, 11, 14, 19, 20, 22]. IHD being common among males was probably related to hormonal effects. In the premenopausal period, females' sex-hormones such as estrogen promote increased HDL and decreased LDL causing a cardio-protective effect [23, 24]. However, a related study in Pakistan showed that central adiposity is significantly higher among females compared with males regarding patients with type 2 diabetes mellitus [25]. Consequently, adiposity is positively related to IHD especially among females [26]. Patients presenting more adiposity may lead to IHD by adipocytokines by the inflammatory pathway causing vascular pathology and establishing atherothrombosis [27]. In addition, differing lifestyle or behavioral patterns between male and female indicate males present higher behavioral risks, e.g., from smoking, that predispose cardiovascular events [28].

However, several related studies have shown that higher BMI leads to risk for IHD [29-31]. The results of statistical analysis in this study found that a higher BMI exhibited a trend of dose response effect to IHD, but without significance. One result from the homogeneity in these diabetes populations is being categorized as overweight to obesity. In addition, patients, who have undergone a long duration with diabetes, may lead to presenting higher BMI. These diabetic populations are at greater risk for IHD; however, the duration of diabetes was not significant in the final model of this study.

The present study found that patients with diabetes, who present hypertensive comorbidity, are at increased risk for IHD. Hypertension is related to IHD and can be described by pathophysiology. The neuro-mediators of hypertension including angiotensin II can promote plasminogen activator inhibitor (PAI-1) expression and increased PAI-1 levels inhibiting the function of tissue plasminogen activator (tPA) resulting in increased myocardial infraction. In addition, the hypertensive stage adds extra pressure that can damage the arterial wall making it more vulnerable and building up plaque associated with atherosclerosis [32]. This study showed that hyperglycemic crisis was related to a high prevalence of IHD with an adjusted ORs of 1.53 (95\% CI, 1.14-2.06). Acute hyperglycemia can attenuate endothelial function 
and reduce nitric oxide (NO) bioavailability [33, 34]. These actions promote monocyte and vascular smooth muscle cell migration into the intima and form macrophage foam cells, characterizing the initial morphological changes of atherosclerosis [35]. The study showed that insulin therapy was related to a high prevalence of IHD with an adjusted ORs of 1.40 (95\% CI, 1.17-1.66). Insulin is more likely to be used among patients with more severe diabetes mellitus of longer duration and more complications such as chronic kidney disease. Therefore, these patients with insulin therapy have an increased number of cardiovascular events.

We have an explanation why IHD related to Health Region 4 in our study. The study showed this region had the highest prevalence of IHD at $6.4 \%$. Health Region 4 is in central Thailand, a peripheral area near the Bangkok Metropolitan Area, where sufficient public health services are much more available. As a result, more patients can access services creating a higher load of reported cases. In addition, the area, which features several agriculture businesses, has more than enough dietary products combined with inappropriate patient dietary behaviors might have promoted a higher risk of cardiovascular disease. Consequently, the patients with diabetes in this area exhibited higher BMIs on average than others area, resulting in a higher risk for IHD [29, 30]. In addition, the patients with diabetic in Health Region 4 had higher age levels than the patients with diabetes in other areas. Although we adjusted age in the final model, the residual effect of age remained.

The study employed a cross-sectional design, and as such, the results could show only factors associated with IHD. The data presented in this study were obtained in the 2012-2013 Thailand DM/HT study of the NHSO from the Medical Research Network of the Consortium of Thai Medical Schools (MedResNet) central data management system. We were aware of missing data from this observational study. Even though this represented a relatively large sample size of the study population and some data were missing as from the nationwide observational (real life situation) study, the associations between factors and outcomes were able to be presented. In the study, we relied on evidence from medical records to identify ischemic heart disease; therefore, a small proportion of individuals with undiagnosed ischemic heart disease may have been misclassified non-differentially. The effect of misclassification decreases the observed effect size (odds ratio) of the associations (toward null). However, the officers who enter data in each hospital received proper training and verified reviewed medical records. The strength of this study was its nation-wide scope for IHD in a diabetic population. Thus, the finding of the study can be generalized and applied in others diabetic population.

\section{Conclusion}

The prevalence of IHD in a diabetic population in this study was $3.54 \%$, higher than the prevalence of IHD in the general population in most related reports. Factors associated with IHD included age, being male, hypertensive comorbidity, being in Health Region 4, presenting hyperglycemic crisis and insulin therapy. Our data emphasized that IHD was a problem among patients with diabetes. Diabetic patients should be regularly assessed for IHD and their risk factors should be better controlled. Moreover, the Ministry of Public Health managers and clinicians should provide further preventative strategies to attenuate cardiovascular disease.

\section{Additional file}

Additional file 1: Univariate analysis of factor associated with ischemic heart disease in diabetic patients. (XLSX $18.7 \mathrm{~kb}$ )

\begin{abstract}
Abbreviations
BMl: body mass index; Cl: confident interval; DBP: diastolic blood pressure; FPG: fasting plasma glucose; GFR_EPI: glomerular infiltration rate calculated by epidemiology collaboration formula; Hb: hemoglobin; HbA1c: hemoglobin A1c; Hct: hematocrit; HDL: high density lipoprotein cholesterol; HT: hypertension; IHD: ischemic heart disease; LDL: Iow density lipoprotein cholesterol; LVH: left ventricular hypertrophy; MoPH: Ministry of Public Health; NHSO: National Health Security Office; SBP: systolic blood pressure; SD: standard deviation; TC: total cholesterol; TG: triglyceride
\end{abstract}

\section{Acknowledgements}

The authors wish to thank the entire staff members of the Department of Military and Community Medicine, Phramongkutklao College of Medicine, for their support in completing this study. The authors thank Professor Colonel Mathirut Mungthin for support and for proofreading this manuscript.

\section{Funding}

No funding was received.

\section{Availability of data and materials}

The datasets generated and/or analyzed during the current study are available in http://www.damus.in.th after the permission of the Thailand DM/ HT study of the Medical Research Network of the Consortium of Thai Medical Schools (MedResNet)

\section{Authors' contributions}

B.S. and R.R. participated in conception, design and statistical analysis; B.S. drafted the manuscripts. Both authors read and approved the final manuscripts.

\section{Ethics approval and consent to participate}

The data of this study were retrieved from database: An assessment in Quality of Care among Patients Diagnosed with Type2 Diabetes and Hypertension Visiting Ministry of Public Health and Bangkok Metropolitan Administration Hospital in Thailand (Thailand DM/HT) after the permission of the Medical Research Network of the Consortium of Thai Medical Schools (MedResNet). The present study was reviewed and approved by the Royal Thai Army Medical Department Institutional Review Board Reference number is S043 h/60_Exp.

Consent for publication

Not applicable.

Competing interests

The authors declare that they have no competing interests. 


\section{Publisher's Note}

Springer Nature remains neutral with regard to jurisdictional claims in published maps and institutional affiliations.

Received: 27 November 2017 Accepted: 16 July 2018

Published online: 27 July 2018

\section{References}

1. Abubakar I, Tillmann T, Banerjee A. Global, regional, and national age-sex specific all-cause and cause-specific mortality for 240 causes of death, 19902013: a systematic analysis for the Global Burden of Disease Study 2013. Lancet (London, England). 2015;385(9963):117-71.

2. Mozaffarian D, Benjamin EJ, Go AS, Arnett DK, Blaha MJ, Cushman M, et al. Heart disease and stroke statistics--2015 update: a report from the American Heart Association. Circulation. 2015;131(4):e29-322.

3. Roth GA, Forouzanfar MH, Moran AE, Barber R, Nguyen G, Feigin VL, et al. Demographic and epidemiologic drivers of global cardiovascular mortality. N Engl J Med. 2015;372(14):1333-41.

4. Diabetes mellitus: a major risk factor for cardiovascular disease. A joint editorial statement by the American Diabetes Association; The National Heart, Lung, and Blood Institute; Th e Juvenile Diabetes Foundation International; The National Institute of Diabetes and Digestive and Kidney Diseases; and The American Heart Association. Circulation 1999;100(10): 1132-1133.

5. Grundy SM, Benjamin IJ, Burke GL, Chait A, Eckel RH, Howard BV, et al. Diabetes and cardiovascular disease: a statement for healthcare professionals from the American Heart Association. Circulation. 1999; 100(10):1134-46.

6. Aguiree F, Brown A, Cho NH, Dahlquist G, Dodd S, Dunning T, et al. IDF diabetes atlas. 2013

7. Wilson PW, D'Agostino RB, Levy D, Belanger AM, Silbershatz H, Kannel WB. Prediction of coronary heart disease using risk factor categories. Circulation. 1998:97(18):1837-47.

8. Avogaro A, Giorda C, Maggini M, Mannucci E, Raschetti R, Lombardo F, et al. Incidence of coronary heart disease in type 2 diabetic men and women: impact of microvascular complications, treatment, and geographic location. Diabetes Care. 2007:30(5):1241-7.

9. Yang ZJ, Liu J, Ge JP, Chen L, Zhao ZG, Yang WY. Prevalence of cardiovascular disease risk factor in the Chinese population: the 2007-2008 China National Diabetes and metabolic disorders study. Eur Heart J. 2012; 33(2):213-20.

10. Krishnan MN. Coronary heart disease and risk factors in India - on the brink of an epidemic? Indian Heart J. 2012:64(4):364-7.

11. Tatsanavivat $P$, Klungboonkrong $V$, Chirawatkul A, Bhuripanyo K, Manmontri $\mathrm{A}$, Chitanondh $\mathrm{H}$, et al. Prevalence of coronary heart disease and major cardiovascular risk factors in Thailand. Int J Epidemiol. 1998;27(3):405-9.

12. Diagnosis and classification of diabetes mellitus. Diabetes Care 2010;33 Suppl 1:S62-S69.

13. Wiréhn A-BE, Östgren CJ, Carstensen JM. Age and gender differences in the impact of diabetes on the prevalence of ischemic heart disease: a population-based register study. Diabetes Res Clin Pract. 2008;79(3):497-502.

14. Jousilahti P, Vartiainen E, Tuomilehto J, Puska P. Sex, age, cardiovascular risk factors, and coronary heart disease: a prospective follow-up study of 14786 middle-aged men and women in Finland. Circulation. 1999;99(9):1165-72.

15. Jani B, Rajkumar C. Ageing and vascular ageing. Postgrad Med J. 2006; 82(968):357-62.

16. GE M, Allen PB, Morgan DR, Hanratty CG, Silke B. Nitric oxide modulation of blood vessel tone identified by arterial waveform analysis. Clin Sci. 2001; 100(4):387-93.

17. Sundquist K, Qvist J, Johansson S-E, Sundquist J. The long-term effect of physical activity on incidence of coronary heart disease: a 12-year follow-up study. Prev Med. 2005:41(1):219-25.

18. Oguma Y, Shinoda-Tagawa T. Physical activity decreases cardiovascular disease risk in women: review and meta-analysis. Am J Prev Med. 2004;26(5):407-18.

19. Ohira T, Iso H. Cardiovascular disease epidemiology in Asia: an overview. Circ J. 2013;77(7):1646-52.

20. Bhatnagar P, Wickramasinghe K, Williams J, Rayner M, Townsend N. The epidemiology of cardiovascular disease in the UK 2014. Heart. 2015; 101(15):1182-9.
21. Sanchis-Gomar F, Perez-Quilis C, Leischik R, Lucia A. Epidemiology of coronary heart disease and acute coronary syndrome. Ann Transl Med. 2016;4(13):256

22. Ueshima H, Sekikawa A, Miura K, Turin TC, Takashima N, Kita Y, et al. Cardiovascular disease and risk factors in Asia: a selected review. Circulation. 2008;118(25):2702-9.

23. Shahar E, Folsom AR, Salomaa W, Stinson VL, McGovern PG, Shimakawa T, et al. Relation of hormone-replacement therapy to measures of plasma fibrinolytic activity. Atherosclerosis risk in communities (ARIC) study investigators. Circulation. 1996;93(11):1970-5.

24. Grady D, Rubin SM, Petitti DB, Fox CS, Black D, Ettinger B, et al. Hormone therapy to prevent disease and prolong life in postmenopausal women. Ann Intern Med. 1992:117(12):1016-37.

25. Akhter O, Fiazuddin F, Shaheryar A, Niaz W, Siddiqui D, Awan S, et al. Central adiposity is significantly higher in female compared to male in Pakistani type 2 diabetes mellitus patients. Indian J Endocrinol Metab. 2015;19(1):72.

26. Canoy D. Distribution of body fat and risk of coronary heart disease in men and women. Curr Opin Cardiol. 2008:23(6):591-8.

27. Golia E, Limongelli G, Natale F, Fimiani F, Maddaloni V, Russo PE, et al. Adipose tissue and vascular inflammation in coronary artery disease. World J Cardiol. 2014;6(7):539.

28. Mons U, Muezzinler A, Gellert C, Schottker B, Abnet CC, Bobak M, et al. Impact of smoking and smoking cessation on cardiovascular events and mortality among older adults: meta-analysis of individual participant data from prospective cohort studies of the CHANCES consortium. BMJ (Clinical research ed). 2015:350:h1551.

29. Flint AJ, Rexrode KM, Hu FB, Glynn RJ, Caspard H, Manson JE, et al. Body mass index, waist circumference, and risk of coronary heart disease: a prospective study among men and women. Obesity Res Clinical Practice. 2010;4(3):e171-e81.

30. Collaboration APCS. Body mass index and cardiovascular disease in the Asia-Pacific region: an overview of 33 cohorts involving 310000 participants. Int J Epidemiol. 2004:33(4):751-8.

31. Joshy G, Korda R, Attia J, Liu B, Bauman A, Banks E. Body mass index and incident hospitalisation for cardiovascular disease in 158546 participants from the 45 and up study. Int J Obes. 2014;38(6):848

32. Libby $P$, Theroux P. Pathophysiology of coronary artery disease. Circulation. 2005;111(25):3481-8

33. Williams SB, Goldfine AB, Timimi FK, Ting HH, Roddy MA, Simonson DC, et al. Acute hyperglycemia attenuates endothelium-dependent vasodilation in humans in vivo. Circulation. 1998;97(17):1695-701.

34. Low Wang CC, Hess CN, Hiatt WR, Clinical Update GAB. Cardiovascular disease in diabetes mellitus: atherosclerotic cardiovascular disease and heart failure in type 2 diabetes mellitus - mechanisms, management, and Clinical Considerations. Circulation. 2016;133(24):2459-502.

35. Perkins JM, Joy NG, Tate DB, Davis SN. Acute effects of hyperinsulinemia and hyperglycemia on vascular inflammatory biomarkers and endothelial function in overweight and obese humans. Am J Physiol Endocrinol Metab. 2015;309(2):E168-76

Ready to submit your research? Choose BMC and benefit from

- fast, convenient online submission

- thorough peer review by experienced researchers in your field

- rapid publication on acceptance

- support for research data, including large and complex data types

- gold Open Access which fosters wider collaboration and increased citations

- maximum visibility for your research: over $100 \mathrm{M}$ website views per year

At BMC, research is always in progress.

Learn more biomedcentral.com/submission 